\title{
Recent advances in hypervalent iodine(III)-catalyzed functionalization of alkenes
}

\author{
Xiang Li, Pinhong Chen * and Guosheng Liu*
}

\author{
Review \\ Address: \\ State Key Laboratory of Organometallic Chemistry, Center for \\ Excellence in Molecular Synthesis, Shanghai Institute of Organic \\ Chemistry, Chinese Academy of Sciences, 345 Lingling Road, \\ Shanghai 200032, China \\ Email: \\ Pinhong Chen ${ }^{*}$ - Pinhongchen@sioc.ac.cn; Guosheng Liu ${ }^{*}$ - \\ gliu@mail.sioc.ac.cn \\ ${ }^{*}$ Corresponding author \\ Keywords: \\ asymmetric catalysis; functionalization of alkenes; hypervalent \\ iodine(III)
}

Beilstein J. Org. Chem. 2018, 14, 1813-1825.

doi:10.3762/bjoc.14.154

Received: 07 April 2018

Accepted: 22 June 2018

Published: 18 July 2018

This article is part of the Thematic Series "Hypervalent iodine chemistry in organic synthesis".

Guest Editor: T. Wirth

(C) $2018 \mathrm{Li}$ et al.; licensee Beilstein-Institut.

License and terms: see end of document.

\begin{abstract}
Hypervalent iodine(III) reagents have been well-developed and widely utilized in functionalization of alkenes, however, generally either stoichiometric amounts of iodine(III) reagents are required or stoichiometric oxidants such as $m$ CPBA are employed to in situ generate iodine(III) species. In this review, recent developments of hypervalent iodine(III)-catalyzed functionalization of alkenes and asymmetric reactions using a chiral iodoarene are summarized.
\end{abstract}

\section{Introduction}

Hypervalent iodine(III) reagents, also named as $\lambda^{3}$-iodanes, have been widely used in organic synthesis since the 1990s, due to their stability, low toxicity and mild reaction conditions [1-10]. Structurally, they always adapt a distorted trigonal bipyramidal geometry in which the less electronegative aryl ring and two lone pairs of electrons are occupying the equatorial positions, and the electronegative ligands are in the apical positions (Figure 1, 1 and 2) [8]. Hypervalent iodine(III) reagents are electrophile in nature, resulting from the node in a hypervalent nonbonding orbital, a 3-center-4-electron (3c-4e) bond ( $\mathrm{L}-\mathrm{I}-\mathrm{L})$, which is formed by the overlap of the $5 \mathrm{p}$ orbital of iodine atom with the orbitals of two ligands (Figure 1) [9].
The chemistry of hypervalent iodine(III) reagents is now a wellestablished area in organic chemistry. They are efficient oxidants in many synthetic transformations, such as oxidation of alcohols and phenols, $\alpha$-functionalization of carbonyl compounds, spirocyclizations, as well as functionalization of alkenes and alkynes [10-17]. In recent years, especially the functionalization of alkenes has attracted much attention [18-20] and in some cases, hypervalent iodine(III) reagents were applied to oxidize transition metals [21-25]. In an alternative way, the electrophilic hypervalent iodine(III) reagents can activate alkenes directly in a metal-free manner. Based on this strategy, dichlorination [26], 1,2-difluorination [27], gem-diflu- 


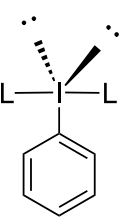

1

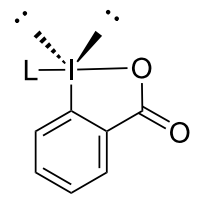

2
$\mathrm{O} \times \mathrm{OO}-$ antibonding $\mathrm{MO}$

$O P 11$ nonbonding $\mathrm{MO}$

$O P \longrightarrow 1$ bonding $\mathrm{MO}$

Figure 1: The structures of hypervalent iodine (III) reagents [8].

orination [28], aminofluorination [29], dioxygenation [30,31], and diamination [32,33] of alkenes could be achieved. Especially, when a nucleophile-tethered alkene is used, a cyclization product was obtained [34,35], although, stoichiometric amounts of hypervalent iodine(III) reagents were required. Due to the metal-like properties of hypervalent iodine(III), a catalytic variant would be feasible (Scheme 1) [10-17]. In the catalytic cycle, hypervalent iodine(III) can be generated by oxidation of iodoarenes in the presence of a suitable external oxidant.

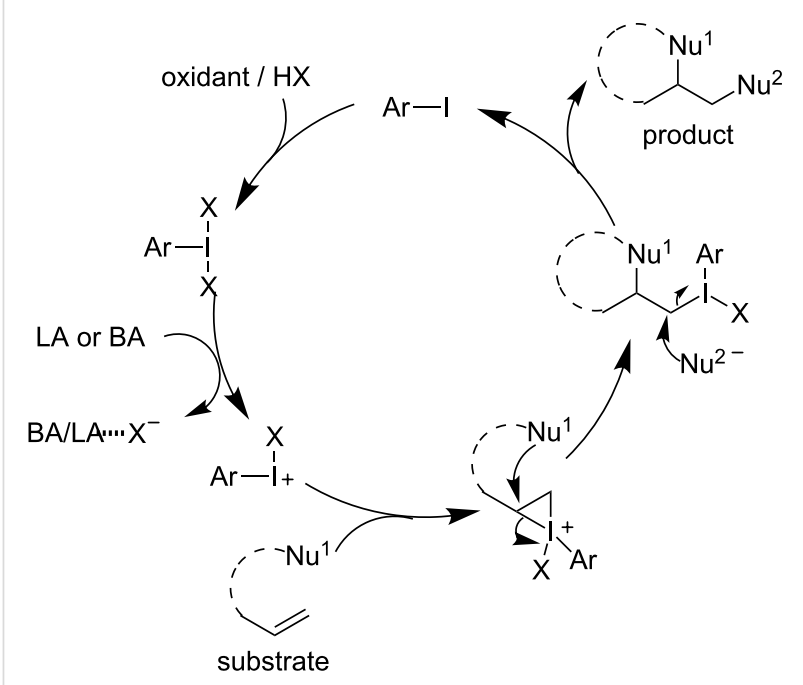

Scheme 1: Hypervalent iodine(III)-catalyzed functionalization of alkenes.

In 1994, Fuchigami and Fujita reported the first hypervalent iodine(III)-catalyzed reaction, in which the iodine(III) reagent was in situ generated by anodic oxidation under electrochemi- cal conditions [36]. Critical to success of this process is that the oxidation potential of the catalysts should be much lower than those of the substrates and products. In addition, inorganic oxidants and peracetic acids can be used as oxidants as well. In 2005 , the Ochiai and Kita groups demonstrated that $m$-chloroperbenzoic acid ( $m$ CPBA) was a better choice for the in situ generation of hypervalent iodine reagents through oxidation of iodoarenes [37,38]. Based on their studies, various hypervalent iodine(III)-catalyzed reactions were developed [39], including asymmetric variations [40-42]. Due to our interest in the functionalization of alkenes, this review focuses on significant progresses in hypervalent iodine(III)-catalyzed functionalization of alkenes as well as some asymmetric reactions employing a chiral iodoarene.

\section{Review Dioxygenation of alkenes}

In 2009, Yan and co-workers reported an efficient catalytic method for the sulfonyloxylactonization of alkenoic acids (Scheme 2) [43], which employed catalytic amounts of hypervalent iodine(III) reagents and $m \mathrm{CPBA}$ as a stoichiometric terminal oxidant. The cyclization of various alkenoic acids in the presence of sulfonic acids such as $p$-toluenesulfonic acid and (+)-10-camphorsulfonic acid afforded the corresponding sulfonyloxylactones $\mathbf{4}$ in good yields. A control experiment indicated that the same result was obtained by replacing $\mathrm{PhI}(\mathrm{OAc})_{2}$ with $\mathrm{PhI}$. In addition, phosphates were suitable nucleophiles in this reaction, giving phosphoryloxylactones in good yields [44]. A similar catalytic cyclization of unsaturated amides leading to oxazolines and dihydrooxazines was developed, in which Selectfluor was used as a stoichiometric oxidant [45].<smiles>C=CCCC(=O)O</smiles>

3

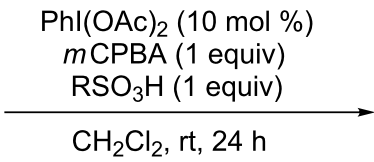

4a, $R=$ tolyl, $82 \%$

4b, $R=(+)$-10-camphoryl, $83 \%$



4 
In contrast to the intramolecular cyclization, the intermolecular reaction is much more attractive. $\mathrm{Li}$ and co-workers reported a syn-diacetoxylation of alkenes, using iodoarenes as catalyst which was oxidized to hypervalent iodine(III) by hydrogen peroxide in the presence of acetic anhydride [46]. As the peroxy compounds can react with alkenes, leading to the anti-products via epoxy intermediates, substrates must be added slowly by a syringe pump to provide reasonable yields and diastereoselectivity. The diastereoselectivity of the reaction can be rationalized by Woodward dioxolane intermediates (Scheme 3).

Stereoselective dioxygenation using catalytic amounts of chiral hypervalent iodine reagents is a comparatively new area in hypervalent iodine chemistry. Fujita and co-workers described a stereoselective oxylactonization reaction in the presence of a chiral hypervalent iodine catalyst [47,48]. Additionally, $m \mathrm{CPBA}$ and trifluoroacetic acid were utilized as terminal oxidants and activators, respectively. This reaction provided a series of 4-oxyisochroman-1-ones, which are found in natural products and bioactive polyketide metabolites. For example, the reaction of hydroxylated substrate $\mathbf{8}$ afforded the dihydrofuranfused isochromanone 9 with up to $91 \%$ ee (Scheme 4, top) [48].
The enantioselective control mode is the same as that described in stoichiometric reactions [49]. Recently, Masson and co-workers described an enantioselective iodoarene-catalyzed sulfonyl- and phoshoryloxylactonization of alkenoic acids $\mathbf{1 1}$ with additional nucleophiles (Scheme 4, bottom) [50], in which a bisamide chiral precatalyst was applied [51]. This reaction provides an efficient access to various interesting enantioenriched $\gamma$-lactones through a tandem sequence in acceptable yields and moderate to excellent enantioselectivities.

Recently, an intermolecular asymmetric dioxygenation reaction has been disclosed by Muñiz and co-workers (Scheme 5) [52]. They found that the chiral iodoarene catalyst $\mathbf{1 3}$, bearing sterically hindered $N$-arylamido substituents, was essential for the asymmetric induction. The NH group engages hydrogen bonding with the acetoxy groups located at an iodine(III) center to form two nine-membered rings, which were confirmed by the crystal structure of the iodine(III) reagent 16 [53]. The hydrogen bonding effect is crucial to a supramolecular helical chiral environment at the iodine center. Mechanistically, the iodine(III) $\mathbf{1 6}$ is activated by triflic acid generating a free coordination site at the iodine(III) center [54]. The coordination of
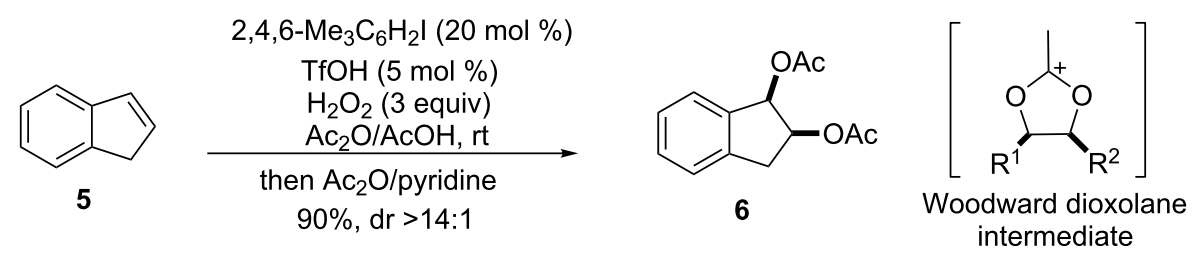

Scheme 3: Catalytic diacetoxylation of alkenes [46].

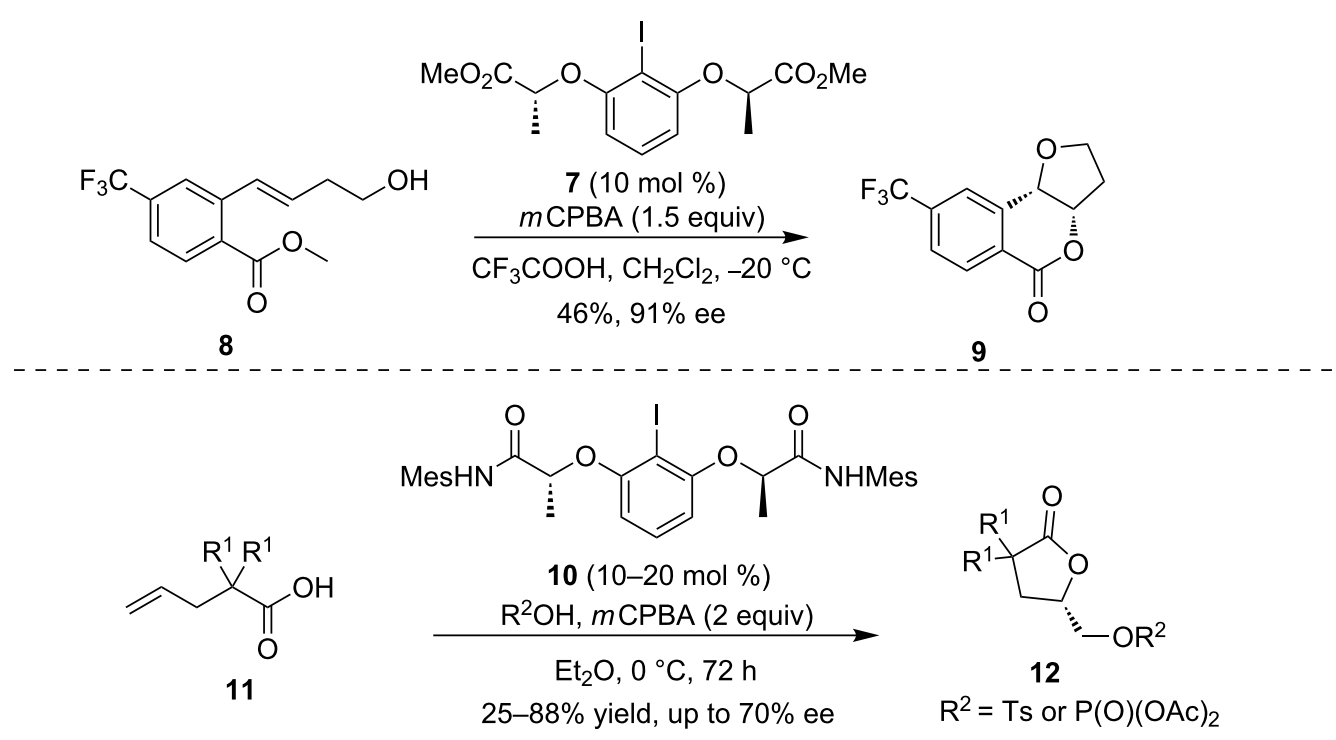

Scheme 4: Intramolecular asymmetric dioxygenation of alkenes $[48,50]$. 

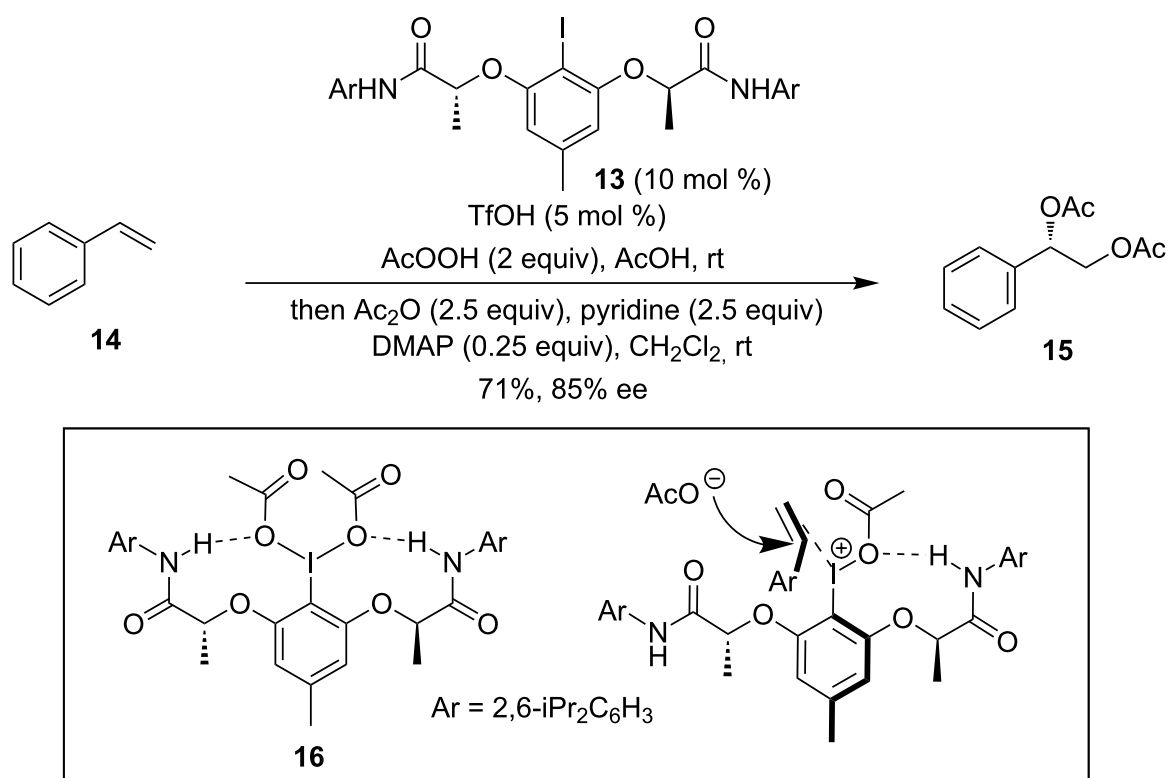

Scheme 5: Intermolecular asymmetric diacetoxylation of styrenes [52].

the alkene to the activated iodine(III) center generates the required prochiral face differentiation and the nucleophilic attack of acetates to the exposed $r$-face establishes the $S$-configured benzylic $\mathrm{C}-\mathrm{O}$ bond.

Without the hydrogen bonding effect, the same reaction with a diester-containing iodoarene catalyst was explored [55]. The sterically hindered adamantyl-substituted catalysts $\mathbf{1 7}$ were demonstrated to be efficient to afford the diacetoxylation products in moderate yields and enantioselectivity when using Selectfluor as a terminal oxidant (Scheme 6).

\section{Diamination of alkenes}

The diamination of alkenes is attractive due to the significance of diamino moieties in diverse fields of the biomedicinal and pharmaceutical sciences. During the study of the hypervalent iodine-mediated intramolecular diamination of alkenes, Blakey and co-workers found that a catalytic version could be achieved in the presence of $m \mathrm{CPBA}$ to give the same product in $85 \%$ yield, which is slightly lower than the yield of the stoichiometric reaction (96\%, Scheme 7) [56].

Later, Wirth and co-workers developed the first highly stereoselective intramolecular diamination of alkenes using a novel, simple hypervalent iodine(III) catalyst 20 (Scheme 8) [57]. In this reaction sodium perborate was the best terminal oxidant rather than $m$ CPBA. Furthermore, the selected protecting group can be removed easily under reducing conditions, providing the free diamine derivatives. However, the substrate scope was limited to alkenes bearing phenyl substituents on the backbone.

On the contrary, the intermolecular diamination of alkenes presented a big challenge under metal-catalyzed conditions, due to the high affinity of the diamine products to metal catalysts.

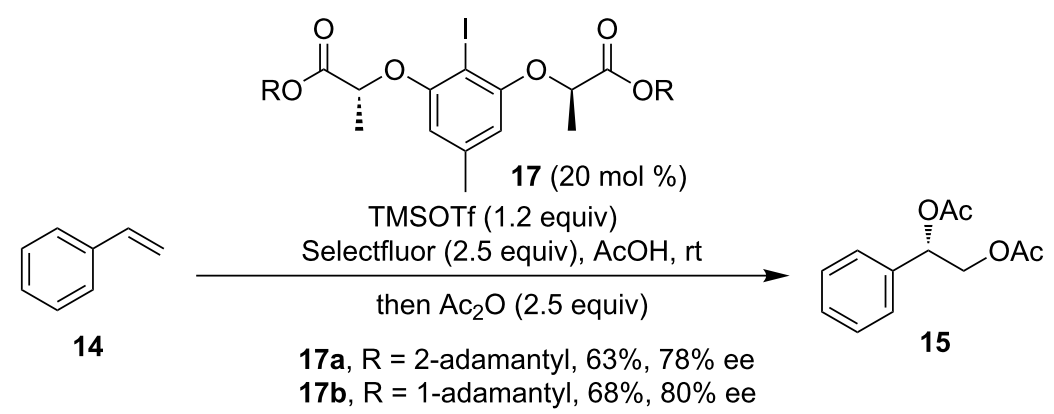

Scheme 6: Diacetoxylation of alkenes with ester groups containing catalysts 17 [55]. 


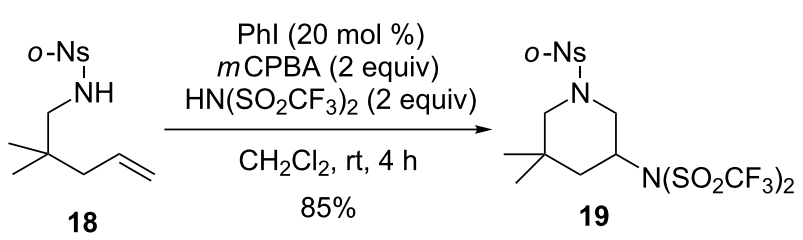

Scheme 7: Intramolecular diamination of alkenes [56].

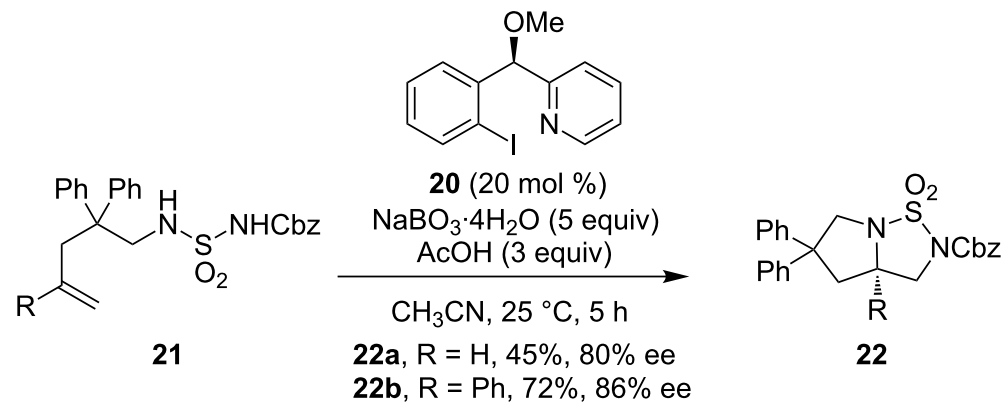

Scheme 8: Intramolecular asymmetric diamination of alkenes [57]

Thus an iodoarene-catalyzed strategy provides a valuable alternative way to the diamination of alkenes. Recently, Muñiz and co-workers reported a chiral iodoarene-catalyzed intermolecular diamination of styrene derivatives (Scheme 9) [58]. An iodoarene precatalyst $\mathbf{2 3}$ bearing the tertiary amide on the lactic side chains was the most effective. $m$ CPBA was used as a stoichiometric oxidant and bismesylimide as an amine source. It is noteworthy that solvent was a key factor to suppress the undesired epoxidation products. Not only terminal styrenes but also internal alkenes were suitable to this reaction, affording the anti-diamination products. The exact mode of stereoinduction with the new catalyst $\mathbf{2 3}$ was examined, and the single crystal X-ray structural analysis of $\mathbf{2 6}$ revealed that a water molecule engages in double hydrogen bonding to form an 11-membered ring, resulting in the chiral helicity. The helical chirality induced in iodine(III) derivatives of $\mathbf{2 3}$ bearing the bislactamide motif was described for $\mathbf{2 7}$ with an efficient differentiation of the enantiotopic faces of the styrene substrate. This protocol acted as an asymmetric gateway to the useful vicinal diamines.<smiles>Cc1cc(O[C@H](C)C(=O)N(C(C)C)C(C)C)c(I)c(O[C@H](C)C(=O)N(C(C)C)C(C)C)c1</smiles>

$23(10-20 \mathrm{~mol} \%)$<smiles>[R]C=Cc1cc[R1]cc1</smiles>
$m$ CPBA (2.1 equiv) $\mathrm{HNMs}_{2}$ (2.5 equiv)

MTBE/TFE 3:1 $35-87 \%, 91-98 \%$ ee

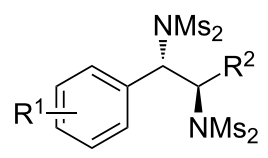
25 $\mathrm{R}^{2}=\mathrm{H}$ or $\mathrm{Me}$<smiles>CC(=O)Oc1cccc(O[C@@H](C)C(=O)N(C(C)C)C(C)C)c1O[C@H](C)C(=O)N(C(C)C)C(C)C</smiles>

26

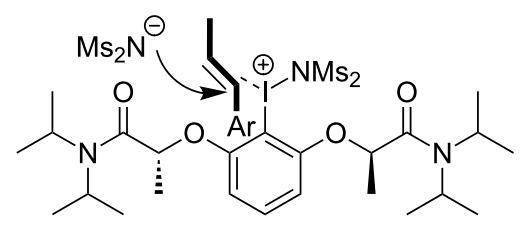

27

Scheme 9: Intermolecular asymmetric diamination of alkenes [58]. 


\section{Aminofluorination of alkenes}

(Difluoroiodo)arenes (Ar-IF 2$)$, which can be prepared from HF with iodosoarenes, are hypervalent iodine compounds suitable for the fluorination of alkenes [59]. Based on Nevado's stoichiometric aminofluorination [29], Shibata, Kita and co-workers reported the iodoarene-catalyzed aminofluorination of amino-tethered alkenes to yield fluorinated cyclic amines [60]. The mechanism for the catalytic aminofluorination of alkenes is shown in Scheme 10. The iodosyl species, $\mathrm{ArI}=\mathrm{O}$, produced by the oxidation of ArI with $m$ CPBA, reacted with HF to provide the corresponding in situ-generated difluoroiodoarenes. An aziridinium intermediate II, which underwent nucleophilic attack by fluoride on the multisubstituted carbon to afford the endo-cyclized products 29, was proposed in Nevado's reaction [29]. Employing the binaphthyldiiodide $\mathbf{3 0}$ as a catalyst was found to be effective for the asymmetric induction. However, the substrate scope of the reaction was still limited to diphenyl-substituted alkenes. This catalytic system could be applied to the aminofluorination of homoallylamines giving $N$-tosyl-3-fluoropyrrolidines in good to high yields [61].
Recently, Jacobsen and co-workers reported the stereoselective synthesis of syn- $\beta$-fluoroaziridine building blocks via a chiral aryl iodide-catalyzed fluorination of allylic amines (Scheme 11) [62]. On the basis of their previous work, the $C_{2}$-symmetric aryl iodide $\mathbf{3 1}$ as a catalyst was applied in this reaction. A $\mathrm{C}\left(\mathrm{sp}^{3}\right)-\mathrm{I}(\mathrm{III})$ intermediate $\mathbf{3 4}$, which was trapped by vicinal nitrogen nucleophiles to form the chiral syn- $\beta$-fluoroaziridine 33, was proposed. Both fluoroaziridines $\mathbf{3 3}$ and $\beta$-fluoropyrrolidines 36 were obtained in good yields and high anti-stereoselectivity. However, the reaction of substrates bearing either two or four methylene groups between the alkene and sulfonamide failed to provide the fluoroheterocycles.

\section{Difluorination of alkenes}

Hara and co-workers reported a vicinal difluorination of unactivated alkenes in the presence of stoichiometric amounts of difluoro iodotoluene [27]. Based on this seminal work, Gilmour and co-workers reported a catalytic difluorination of alkenes using an inexpensive $p$-iodotoluene as the catalyst and Selectfluor as the terminal oxidant [63]. Terminal olefins proved to be

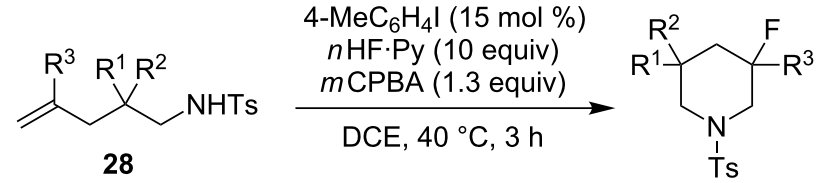

29

$30(15 \mathrm{~mol} \%)$<smiles>C=CCC(CN[18F])(c1ccccc1)c1ccccc1</smiles>

28c

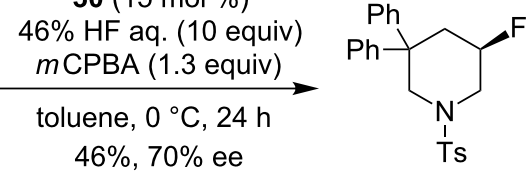

$29 c$ 29a, $R^{1}=R^{2}=M e, R^{3}=H, 73 \%$

29b, $R^{1}=R^{2}=M e, R^{3}=M e, 61 \%$

29c, $R^{1}=R^{2}=P h, R^{3}=H, 68 \%$

29d, $R^{1}=M e, R^{2}=H, R^{3}=H, 77 \%$, dr $74: 26$<smiles>Ic1ccc2ccccc2c1-c1c(I)ccc2ccccc12</smiles>

30



Scheme 10: lodoarene-catalyzed aminofluorination of alkenes [60,61]. 




Scheme 11: lodoarene-catalyzed aminofluorination of alkenes [62].

viable substrates for this reaction. It is worth noting that the ratio of amines and HF was important for obtaining reasonable yields. Indeed, excellent ${ }^{19} \mathrm{~F}$ NMR yields albeit lower isolated yields were obtained in this reaction (Scheme 12). In an attempt to induce enantioselectivity, the chiral aryl iodide derivative 39 only gave a moderate enantioselectivity $(22 \%$ ee).

Meantime, a similar work was independently reported by Jacobsen and co-workers, in which the reactive iodoarene difluoride could be in situ generated by oxidation of aryl iodide $\mathbf{4 0}$ with $m$ CPBA [64]. The reaction showed a wide substrate scope, with toleration of terminal, internal alkenes as well as electrondeficient unsaturated carbonyl compounds (Scheme 13). In general, terminal alkenes were found to undergo 1,2-difluorination 42a-c. The reaction of internal alkenes usually afforded the syn-difluorination products $\mathbf{4 2 d}$ and $42 \mathrm{e}$. However, the oppo- site result was observed in the reaction of the $o$-nitrostyrene derivative $\mathbf{4 2 f}$, due to the Lewis basicity of the nitro group. These stereochemical outcomes were also observed in the reaction of acrylamides by means of anchimeric assistance.

Preliminary studies to identify asymmetric variants indicated that, in the presence of lactate-based chiral iodoarene catalyst 43 , the cinnamamide $41 \mathrm{i}$ could be transformed to the corresponding difluorination product $\mathbf{4 2} \mathbf{i}$ with excellent enantioselectivity and high stereoselectivity, albeit in moderate yields (Scheme 14, top) [64]. Inspired by the propensity for such anchimeric assistance in these reactions, an enantio- and diastereoselective catalytic fluorination was developed by the same group (Scheme 14, bottom) [65] using the lactate-based resorcinol derivative $\mathbf{4 4}$ as the catalyst. By this route chiral 4-fluoroisochromanones 46 could be accomplished in high enantio-<smiles>C=C[14CH2]COC(=O)c1ccc(OC)cc1</smiles>

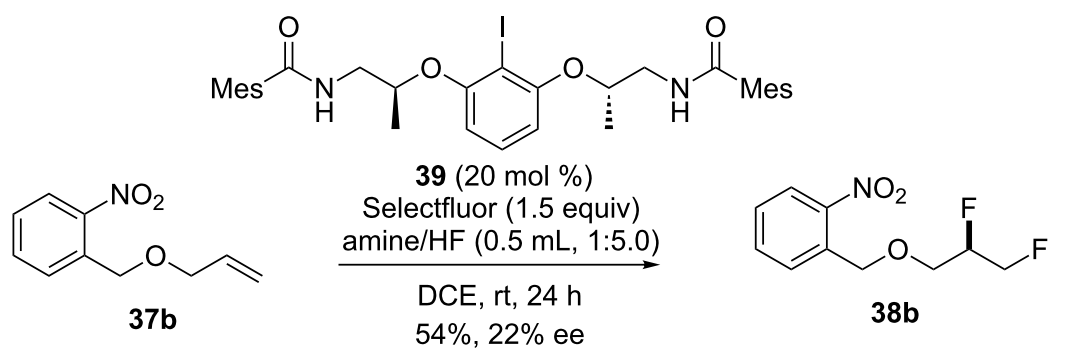


<smiles>CC(=O)COc1cc(OCC(C)=O)c(I)c(OCC(C)=O)c1</smiles>

$40(20 \mathrm{~mol} \%)$

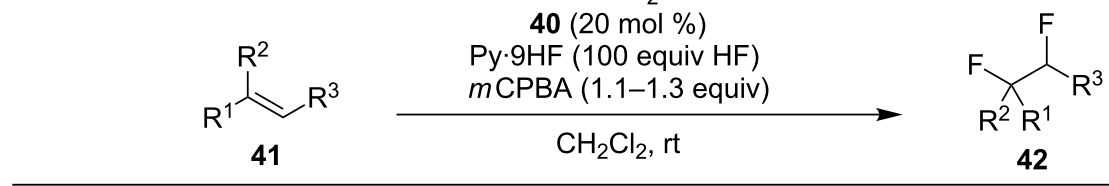<smiles>FCC(F)Cc1ccc(C(F)(F)F)cc1</smiles>

42a $61 \%$<smiles>FCC(F)Cc1ccccc1</smiles>

42b $44 \%$<smiles>FCC(F)CCN(Cc1ccccc1)Cc1ccccc1</smiles>

42c $60 \%$<smiles>CC1(F)Cc2ccccc2C1F</smiles>

42d $60 \%$, dr $5: 1$<smiles>CC(F)C(F)c1cc([N+](=O)[O-])cc([N+](=O)[O-])c1</smiles>

42e $36 \%, d r>19: 1$<smiles>CC(F)C(F)c1ccccc1[N+](=O)[O-]</smiles>

42f $79 \%, d r>19: 1$<smiles>NC(=O)C(F)(C(N)=O)C(F)c1ccccc1</smiles>

42g $70 \%, d r>19: 1$<smiles>CC(C)CC(F)C(C(N)=O)[N+](=O)[O-]</smiles>

42h $90 \%, d r>19: 1$

Scheme 13: lodoarene-catalyzed 1,2-difluorination of alkenes [64]

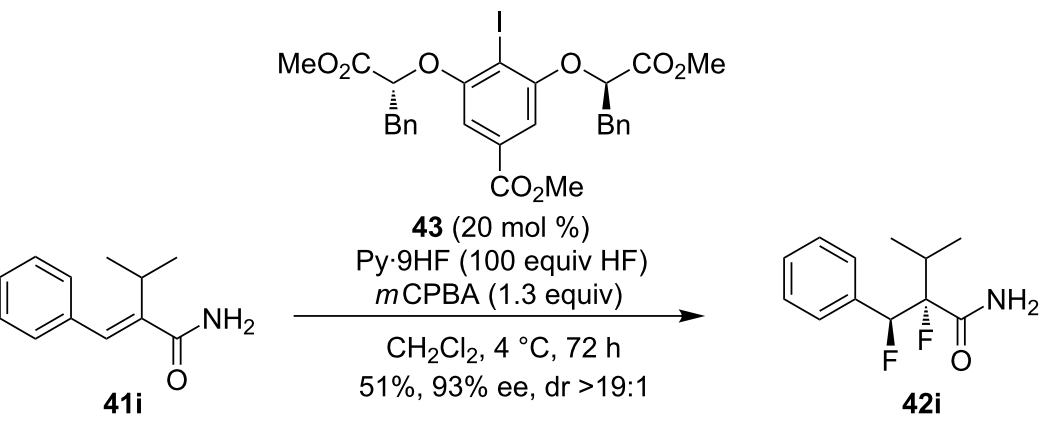<smiles>CC(Oc1cccc(OC(C)C(=O)OCc2ccccc2)c1I)C(=O)Cc1ccccc1</smiles><smiles>C/C=C/c1ccccc1C(C)=O</smiles>

45

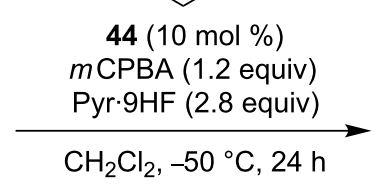

$68 \%, 95 \%$ ee<smiles>O=C1OC([N+](=O)[O-])C(F)c2ccccc21</smiles>

46<smiles>COC(=O)c1ccccc1C(F)C(C)C(C)(C)O</smiles>

47

Scheme 14: lodoarene-catalyzed asymmetric fluorination of styrenes $[64,65]$.

and diastereoselectivity. The same I(III) intermediate 47 was trapped by an $o$-carboxylic ester group leading to the $s y n$-diastereoisomeric outcome.
An aryl rearrangement might be realized via benzenium ions in the iodine(III)-mediated reactions of styrenes [66]. Oyamada and co-workers reported the synthesis of 2,2-difluoroethyl- 
arenes mediated by iodine(III) reagents. Moreover, they found that this fluorination also proceeds with catalytic amounts of the iodoarenes in the presence of $m \mathrm{CPBA}$ as a terminal oxidant, albeit in lower yields (Scheme 15) [67]. Mechanistically, the 1,2-aryl shift could arise via phenonium intermediates 49 to deliver the geminal difluorination products.

Recently, Jacobsen and co-workers reported a highly enantioselective gem-difluorination of various cinnamic acid derivatives through the same oxidative rearrangement (Scheme 16) [68] During the catalysts screening, they found that the benzylic unit in the catalysts was essential for a high enantioselectivity (52 vs 53). Moreover, the more electron-deficient 3,4,5-trifluorophenyl analog $\mathbf{5 4}$ was found to be less enantioselective. The authors proposed that the benzylic groups can stabilize the cationic intermediates and/or transition states through cation $-\pi$ interactions, which play an important role in the stereodifferentiation step.

\section{Other functionalizations of alkenes}

In addition to heteroatom-containing nucleophiles, electron-rich aromatic groups were also reported as nucleophiles to form the $\mathrm{C}-\mathrm{C}$ bonds $[69,70]$. In this context, Lupton, Hutt and co-workers reported an iodobenzene-catalyzed 1,2-olefin functionalization via $\mathrm{C}-\mathrm{C}$ and $\mathrm{C}-\mathrm{O}$ bond formation, in which electron-rich aromatic groups and vinylogous esters acting as independent nucleophiles to provide oxabicyclo[3.2.1] octanes (Scheme 17) [71]. Mechanistically, the olefin is activated by

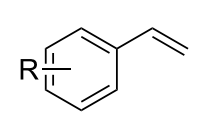

47

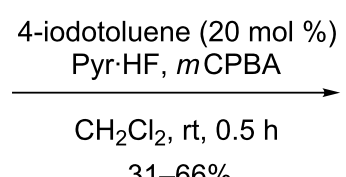

$31-66 \%$

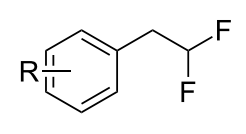

48

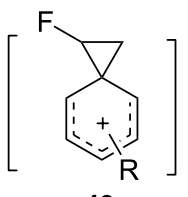

49

Scheme 15: Gem-difluorination of styrenes [67].
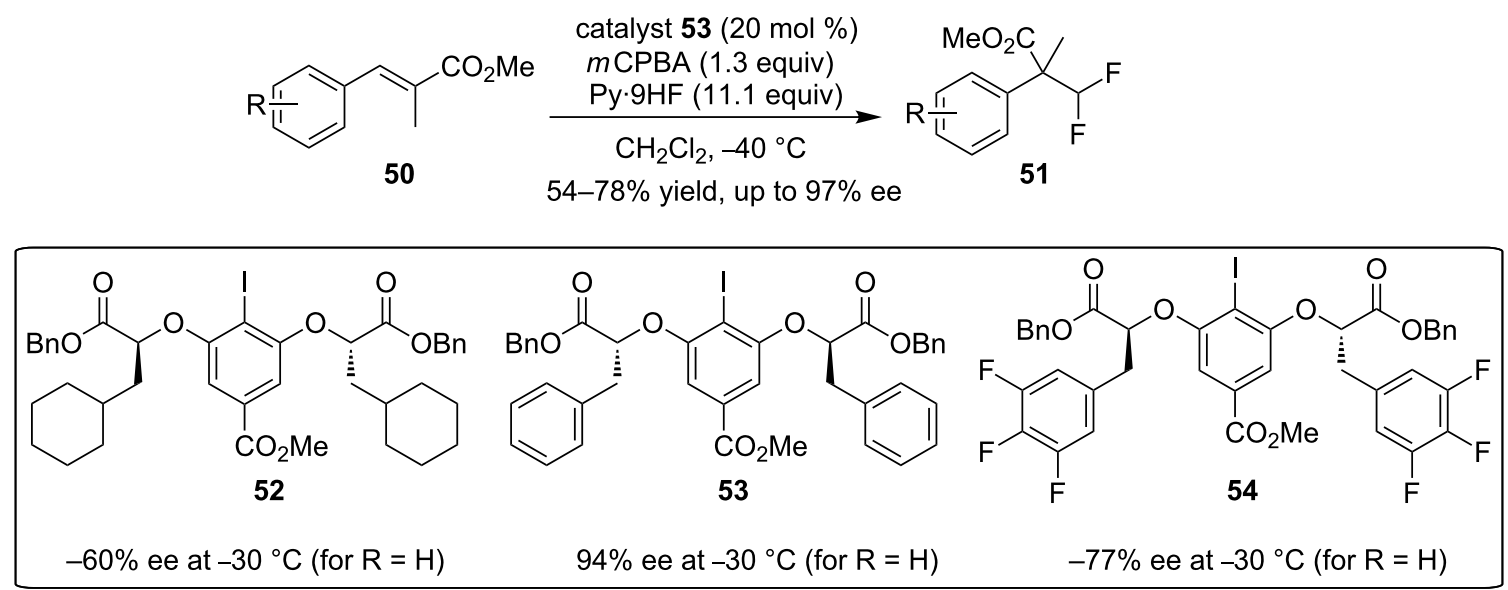

Scheme 16: Asymmetric gem-difluorination of cinnamic acid derivatives [68].<smiles>C=C(C)CC1(Cc2ccc(OC)cc2)CCC(OCC)C=C1C</smiles>

55

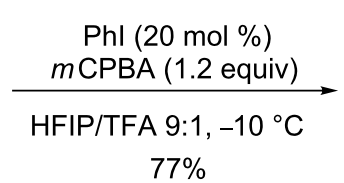

$77 \%$<smiles>CC12CC(=O)C=C3OC(C)(CC4(C=CC(=O)C=C4)C1)C32C</smiles>

56

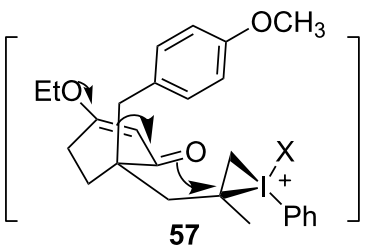


iodine(III) to form species $\mathbf{5 7}$ which is followed by first a nucleophilic attack from the vinylogous ester, then by the aromatic group, providing the final outcomes.

Wirth and co-workers developed an oxidative rearrangement of alkenes to chiral $\alpha$-aryl ketones, in which electron-deficient chiral lactic acid-based hypervalent iodine reagents were synthesized and applied [72]. The regioselective methoxylation of diphenyl alkene with chiral hypervalent iodine $\mathbf{5 8}$ afforded a mixture of 60 and 61 in moderated yield and good enantioselectivity. However, the catalytic reaction afforded the opposite regioselectivity to give rearrangement product $\mathbf{6 0}$ in dramatically decreased yield and enantioselectivity (Scheme 18). Similar oxidative rearrangement reactions with haloalkenes generated $\alpha$-halo ketones [73].

NBS also oxidizes iodoarene $\mathbf{6 5}$ to form the brominating agent 66 [74]. Braddock and co-workers reported an organocatalyzed transformation of electrophilic bromines to alkenes, using ortho-substituted iodobenzene $\mathbf{6 2}$ as an organocatalyst (Scheme 19) [75]. A control experiment indicated that only trace amounts of products were observed in the absence of iodoarene catalyst $(2 \%)$. A similar work involving a rearrangement of imides, which delivered $\alpha, \alpha$-disubstituted- $\alpha$-hydroxycarboxylamides, was disclosed by Gulder and co-workers [76].

This catalytic system was applied to the bromination of alkenes by Gulder and co-workers. For example, the iodine(III)-catalyzed halocyclization of methacrylamide $\mathbf{6 8}$ generated the brominated oxindole 69 (Scheme 20) [77]. In addition, electronrich aromatics present in the substrates were also brominated. During the screening of the iodoarene pre-catalysts, a dihalogenation product was detected in the presence of iodoarenes bearing electron-donating side chains 70. A diastereoselective dihalogenation method was established under mild conditions [78]. The authors proposed a radical pathway involving the in

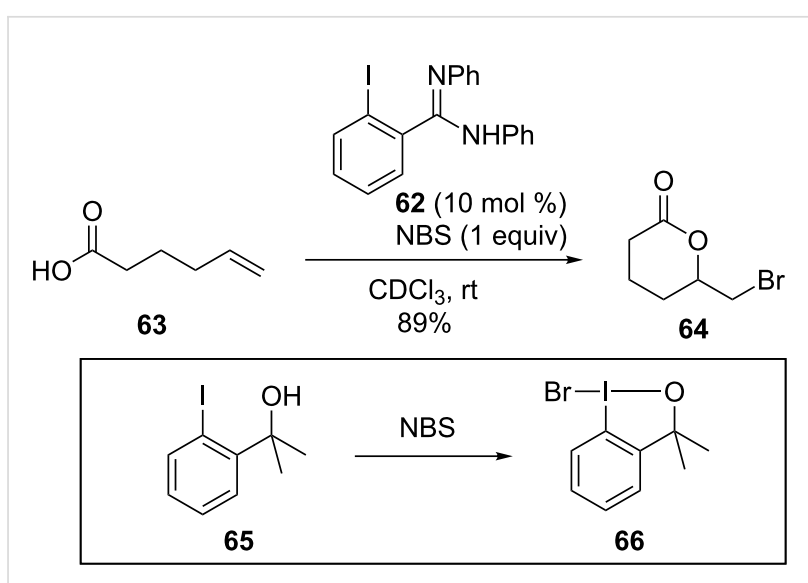

Scheme 19: Bromolactonization of alkenes [75].

situ generation of $\mathrm{Br}_{2}$, which opens the avenue for a reliable, ecologically benign, and safe dibromination method.

\section{Conclusion}

In the last two decades, great progress was made in hypervalent iodine(III) catalytic systems. On the basis of these improvements, it is no longer necessary to prepare hypervalent iodine compounds, as the iodide precursors can be used catalytically. The recently developed enantioselective hypervalent iodine(III)-mediated transformations could be a breakthrough for the application of these reagents in chiral synthesis.

As outlined, there have been achieved great advances in the hypervalent iodine-mediated functionalization of alkenes. However, the types of chiral iodoarene catalysts are limited and new chiral iodoarene scaffolds should be developed for highly stereoselective reactions.

Compared to the diverse reactivity profiles of transition metalcatalyzed functionalization of alkenes, hypervalent iodine (III)-

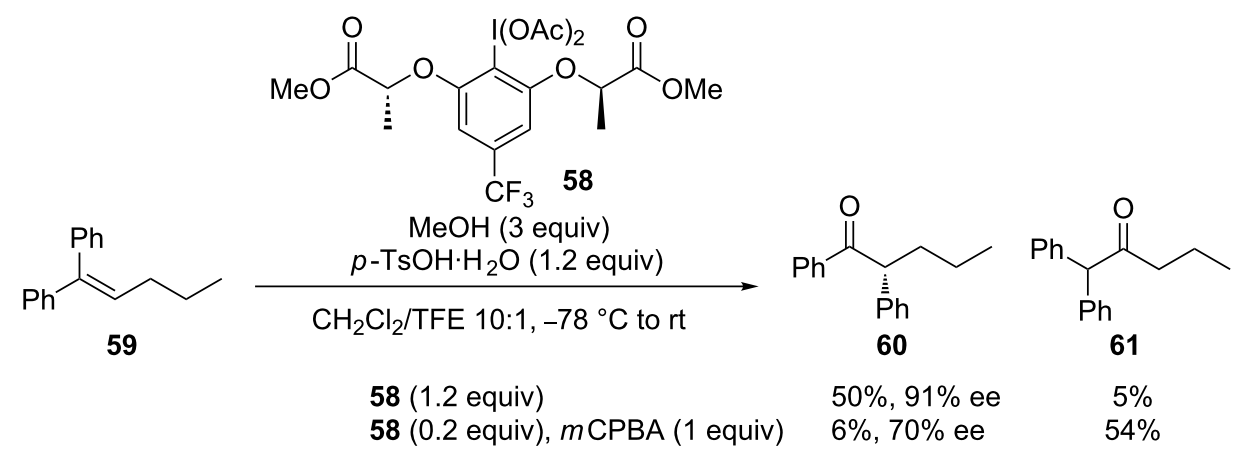

Scheme 18: Asymmetric oxidative rearrangements of alkenes [72]. 


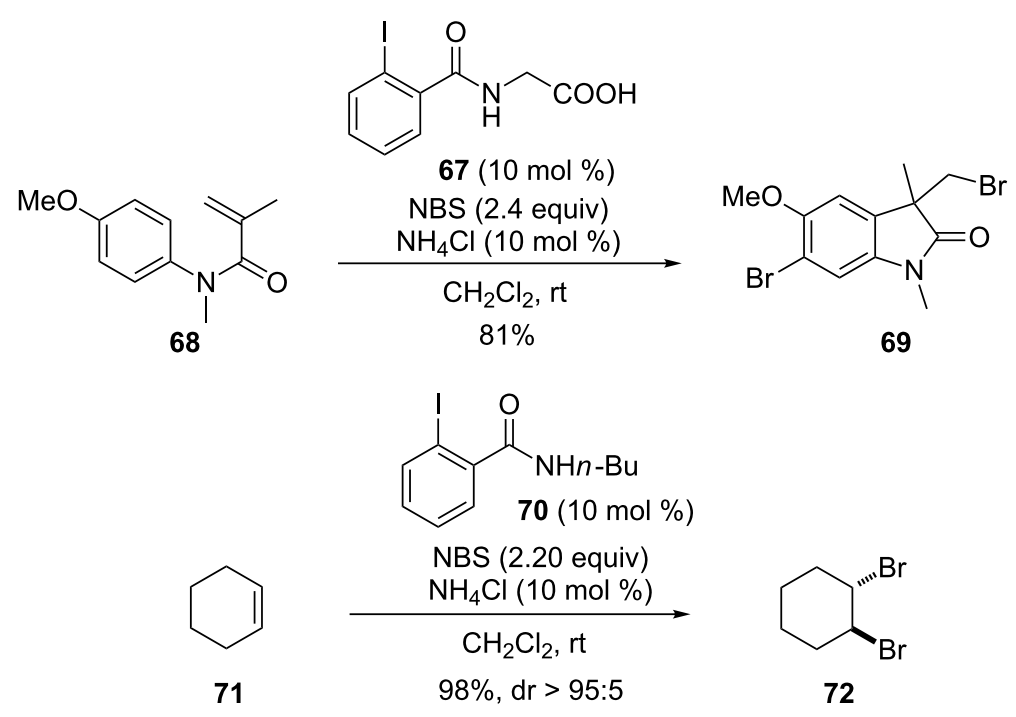

Scheme 20: Bromination of alkenes [77,78].

mediated reactions are limited to nucleophilic substitution processes. Recently, Liu and co-workers reported a novel cooperative strategy by combining palladium catalysis and hypervalent iodine-mediated reactions to achieve the intermolecular oxycarbonylation [79], azidocarbonylation [80] and fluorocarbonylation [81] of alkenes. Mechanistic studies showed that $\mathrm{PhI}(\mathrm{OAc})_{2}$ is activated by the aid of $\mathrm{BF}_{3} \cdot \mathrm{OEt}_{2}$ and then reacts with an alkene to form a three-membered iodonium ion intermediate 75. Subsequently, this intermediate is attacked by the palladium catalyst under a $\mathrm{CO}$ atmosphere to form the alkyl palladium species 76. Finally, the reductive elimination at the iodine(III) center and $\mathrm{CO}$ insertion into the newly formed $\mathrm{C}-\mathrm{Pd}$ bond, affords the oxycarbonylation products $\mathbf{7 4}$ (Scheme 21). This strategy provides an attractive development tendency in hypervalent iodine(III) chemistry. It is fascinating to realize such transformations with catalytic amounts of iodoarenes as well as chiral iodoarene reagents to induce enantioselectivity.

\section{Acknowledgements}

We are grateful for financial support from the National Nature Science Foundation of China (Nos. 21532009, 21672236, 21790330 and 21761142010), the National Basic Research Program of China (Grant 973-2015CB856600), the Shanghai Rising-Star Program (17QA1405200), the Strategic Priority Research Program (No. XDB20000000), and the Key Research Program of Frontier Science (No. QYZDJSSW-SLH055) of the Chinese Academy of Sciences.

\section{References}

1. Varvoglis, A. The Organic Chemistry of Polycoordinated lodine; VCH Publishers, Inc.: New York, 1992.

2. Akiba, K.-y., Ed. Chemistry of Hypervalent Compounds; Wiley-VCH: New York, 1999.

3. Zhdankin, V. V.; Stang, P. J. In Chemistry of Hypervalent Compounds; Akiba, K.-y., Ed.; VCH Publishers: New York, 1999.

4. Ochiai, M. In Chemistry of Hypervalent Compounds; Akiba, K.-y., Ed.; VCH Publishers: New York, 1999.

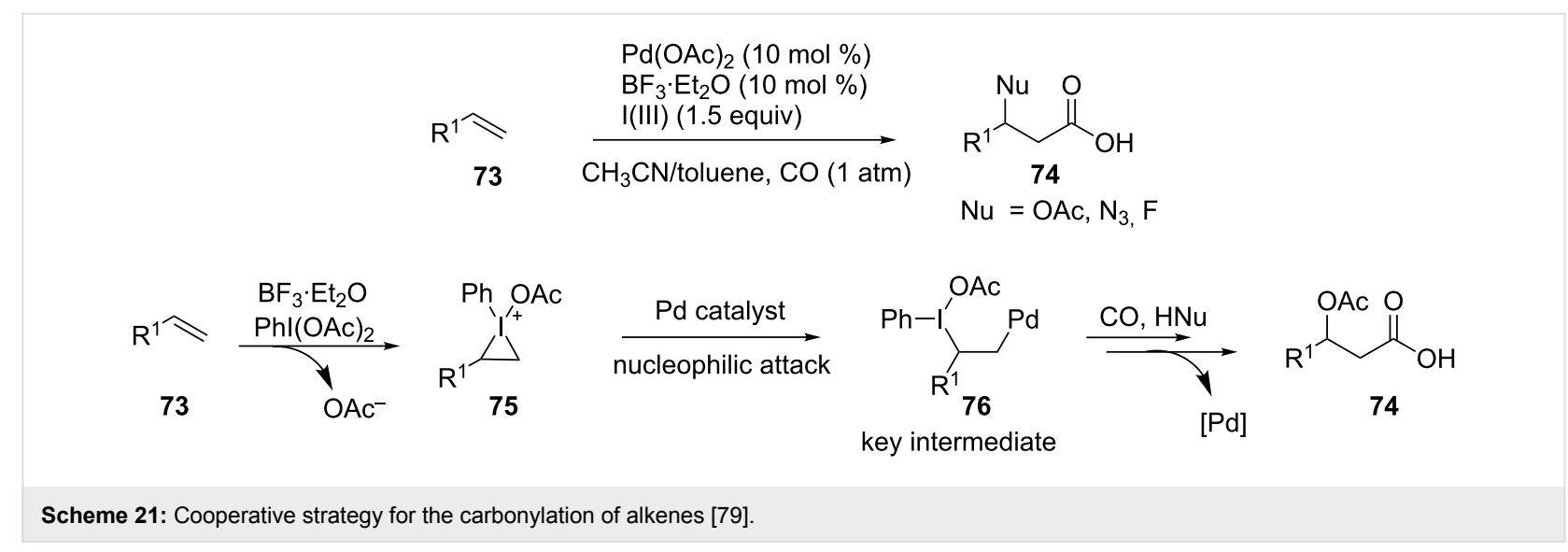


5. Varvoglis, A. Tetrahedron 2010, 66, 5739-5744 doi:10.1016/j.tet.2010.04.126

6. Zhdankin, V. V. Hypervalent lodine Chemistry: Preparation, Structure and Synthetic Application of Polyvalent lodine Compounds; John Wiley \& Sons Ltd.: New York, 2014.

7. Kaiho, T., Ed. lodine Chemistry and Applications; John Wiley \& Sons, Inc.: New York, 2015.

8. Wirth, T. Top. Curr. Chem. 2003, 224, 1-4. doi:10.1007/3-540-46114-0_1

9. Merritt, E. A.; Olofesson, B. Angew. Chem., Int. Ed. 2009, 48, 9052-9070. doi:10.1002/anie.200904689

10. Zhdankin, V. V.; Stang, P. J. Chem. Rev. 2008, 108, 5299-5358. doi:10.1021/cr800332c

11. Ochiai, M.; Miyamoto, K. Eur. J. Org. Chem. 2008, 4229-4239. doi:10.1002/ejoc.200800416

12. Dohi, T.; Kita, Y. Chem. Commun. 2009, 2073-2085. doi:10.1039/b821747e

13. Küpper, F. C.; Feiters, M. C.; Olofsson, B.; Kaiho, T.; Yanagida, S.; Zimmermann, M. B.; Carpenter, L. J.; Luther, G. W., III; Lu, Z.; Jonsson, M.; Kloo, L. Angew. Chem., Int. Ed. 2011, 50, 11598-11620. doi:10.1002/anie.201100028

14. Merritt, E. A.; Olofsson, B. Synthesis 2011, 517-538. doi:10.1055/s-0030-1258328

15. Parra, A.; Reboredo, S. Chem. - Eur. J. 2013, 19, 17244-17260. doi:10.1002/chem.201302220

16. Berthiol, F. Synthesis 2015, 47, 587-603. doi:10.1055/s-0034-1379892

17. Yoshimura, A.; Zhdankin, V. V. Chem. Rev. 2016, 116, 3328-3435 doi:10.1021/acs.chemrev.5b00547

18. Muñiz, K. Chem. Soc. Rev. 2004, 33, 166-174. doi:10.1039/B307102M

19. Donohoe, T. J.; Callens, C. K. A.; Flores, A.; Lacy, A. R.; Rathi, A. H. Chem. - Eur. J. 2011, 17, 58-76. doi:10.1002/chem.201002323

20. Togni, A.; Grützmacher, H., Eds. Catalytic Heterofunctionalization; Wiley-VCH: Weinheim, 2001. doi:10.1002/3527600159

21. Deprez, N. R.; Sanford, M. S. Inorg. Chem. 2007, 46, 1924-1935. doi:10.1021/ic0620337

22. Muñiz, K. Angew. Chem., Int. Ed. 2009, 48, 9412-9423. doi:10.1002/anie.200903671

23. Xu, L.-M.; Li, B.-J.; Yang, Z.; Shi, Z.-J. Chem. Soc. Rev. 2010, 39, 712-733. doi:10.1039/B809912J

24. Sehnal, P.; Taylor, R. J. K.; Fairlamb, I. J. S. Chem. Rev. 2010, 110 , 824-889. doi:10.1021/cr9003242

25. McDonald, R. I.; Liu, G.; Stahl, S. S. Chem. Rev. 2011, 111, 2981-3019. doi:10.1021/cr100371y

26. Nicolaou, K. C.; Simmons, N. L.; Ying, Y.; Heretsch, P. M.; Chen, J. S. J. Am. Chem. Soc. 2011, 133, 8134-8137. doi:10.1021/ja202555m

27. Hara, S.; Nakahigashi, J.; Ishi-i, K.; Sawaguchi, M.; Sakai, H.; Fukuhara, T.; Yoneda, N. Synlett 1998, 495-496. doi:10.1055/s-1998-1714

28. Hara, S.; Nakahigashi, J.; Ishi-i, K.; Fukuhara, T.; Yoneda, N. Tetrahedron Lett. 1998, 39, 2589-2592. doi:10.1016/S0040-4039(98)00276-7

29. Kong, W.; Feige, P.; de Haro, T.; Nevado, C. Angew. Chem., Int. Ed. 2013, 52, 2469-2473. doi:10.1002/anie.201208471

30. Zhong, W.; Yang, J.; Meng, X.; Li, Z. J. Org. Chem. 2011, 76, 9997-10004. doi:10.1021/jo201752y

31. Tellitu, I.; Domínguez, E. Tetrahedron 2008, 64, 2465-2470. doi:10.1016/j.tet.2007.12.045

32. Souto, J. A.; Martínez, C.; Velilla, I.; Muñiz, K. Angew. Chem., Int. Ed. 2013, 52, 1324-1328. doi:10.1002/anie.201206420
33. Moriarty, R. M.; Khosrowshahi, J. S. Tetrahedron Lett. 1986, 27 , 2809-2812. doi:10.1016/S0040-4039(00)84648-1

34. Romero, R. M.; Wöste, T. H.; Muñiz, K. Chem. - Asian J. 2014, 9 , 972-983. doi:10.1002/asia.201301637

35. Kohlhepp, S. V.; Gulder, T. Chem. Soc. Rev. 2016, 45, 6270-6288. doi:10.1039/C6CS00361C

36. Fuchigami, T.; Fujita, T. J. Org. Chem. 1994, 59, 7190-7192. doi:10.1021/jo00103a003

37. Ochiai, M.; Takeuchi, Y.; Katayama, T.; Sueda, T.; Miyamoto, K. J. Am. Chem. Soc. 2005, 127, 12244-12245. doi:10.1021/ja0542800

38. Dohi, T.; Maruyama, A.; Yoshimura, M.; Morimoto, K.; Tohma, H.; Kita, Y. Angew. Chem., Int. Ed. 2005, 44, 6193-6196. doi:10.1002/anie.200501688

39. Singh, F. V.; Wirth, T. Chem. - Asian J. 2014, 9, 950-971. doi:10.1002/asia.201301582

40. Dohi, T.; Maruyama, A.; Takenaga, N.; Senami, K.; Minamitsuji, Y.; Fujioka, H.; Caemmerer, S. B.; Kita, Y. Angew. Chem., Int. Ed. 2008, 47, 3787-3790. doi:10.1002/anie.200800464

41. Quideau, S.; Lyvinec, G.; Marguerit, M.; Bathany, K.; Ozanne-Beaudenon, A.; Buffeteau, T.; Cavagnat, D.; Chénedé, A. Angew. Chem., Int. Ed. 2009, 48, 4605-4609. doi:10.1002/anie.200901039

42. Fujita, M. Tetrahedron Lett. 2017, 58, 4409-4419. doi:10.1016/j.tetlet.2017.10.019

43. Yan, J.; Wang, H.; Yang, Z.; He, Y. Synlett 2009, 2669-2672. doi:10.1055/s-0029-1217977

44. Zhou, Z.-S.; He, X.-H. Tetrahedron Lett. 2010, 51, 2480-2482. doi:10.1016/j.tetlet.2010.02.153

45. Alhalib, A.; Kamouka, S.; Moran, W. J. Org. Lett. 2015, 17, 1453-1456. doi:10.1021/acs.orglett.5b00333

46. Zhong, M.; Liu, S.; Yang, J.; Meng, X.; Li, Z. Org. Lett. 2012, 14, 3336-3339. doi:10.1021/ol301311e

47. Fujita, M.; Mori, K.; Shimogaki, M.; Sugimura, T. Org. Lett. 2012, 14, 1294-1297. doi:10.1021/ol300185u

48. Shimogaki, M.; Fujita, M.; Sugimura, T. Eur. J. Org. Chem. 2013, 7128-7138. doi:10.1002/ejoc.201300959

49. Fujita, M.; Yoshida, Y.; Miyata, K.; Wakisaka, A.; Sugimura, T. Angew. Chem., Int. Ed. 2010, 49, 7068-7071. doi:10.1002/anie.201003503

50. Gelis, C.; Dumoulin, A.; Bekkaye, M.; Neuville, L.; Masson, G. Org. Lett. 2017, 19, 278-281. doi:10.1021/acs.orglett.6b03631

51. Uyanik, M.; Yasui, T.; Ishihara, K. Angew. Chem., Int. Ed. 2010, 49, 2175-2177. doi:10.1002/anie.200907352

52. Haubenreisser, S.; Wöste, T. H.; Martínez, C.; Ishihara, K.; Muñiz, K. Angew. Chem., Int. Ed. 2016, 55, 413-417. doi:10.1002/anie.201507180

53. Uyanik, M.; Yasui, T.; Ishihara, K. Angew. Chem., Int. Ed. 2013, 52, 9215-9218. doi:10.1002/anie.201303559

54. Kang, Y.-B.; Gade, L. H. J. Am. Chem. Soc. 2011, 133, 3658-3667. doi:10.1021/ja110805b

55. Wöste, T. H.; Muñiz, K. Synthesis 2016, 48, 816-827. doi:10.1055/s-0035-1561313

56. Kong, A.; Blakey, S. B. Synthesis 2012, 44, 1190-1198. doi:10.1055/s-0031-1290591

57. Mizar, P.; Laverny, A.; El-Sherbini, M.; Farid, U.; Brown, M.; Malmedy, F.; Wirth, T. Chem. - Eur. J. 2014, 20, 9910-9913. doi:10.1002/chem.201403891

58. Muñiz, K.; Barreiro, L.; Romero, R. M.; Martínez, C. J. Am. Chem. Soc. 2017, 139, 4354-4357. doi:10.1021/jacs.7b01443 
59. Yoneda, N. J. Fluorine Chem. 2004, 125, 7-17. doi:10.1016/S0022-1139(03)00159-3

60. Suzuki, S.; Kamo, T.; Fukushi, K.; Hiramatsu, T.; Tokunaga, E.; Dohi, T.; Kita, Y.; Shibata, N. Chem. Sci. 2014, 5, 2754-2760. doi:10.1039/C3SC53107D

61. Kitamura, T.; Miyake, A.; Muta, K.; Oyamada, J. J. Org. Chem. 2017, 82, 11721-11726. doi:10.1021/acs.joc.7b01266

62. Mennie, K. M.; Banik, S. M.; Reichert, E. C.; Jacobsen, E. N. J. Am. Chem. Soc. 2018, 140, 4797-4802. doi:10.1021/jacs.8b02143

63. Molnár, I. G.; Gilmour, R. J. Am. Chem. Soc. 2016, 138, 5004-5007. doi:10.1021/jacs.6b01183

64. Banik, S. M.; Medley, J. W.; Jacobsen, E. N. J. Am. Chem. Soc. 2016, 138, 5000-5003. doi:10.1021/jacs.6b02391

65. Woerly, E. M.; Banik, S. M.; Jacobsen, E. N. J. Am. Chem. Soc. 2016, 138, 13858-13861. doi:10.1021/jacs.6b09499

66. Farid, U.; Malmedy, F.; Claveau, R.; Albers, L.; Wirth, T. Angew. Chem., Int. Ed. 2013, 52, 7018-7022. doi:10.1002/anie.201302358

67. Kitamura, T.; Muta, K.; Oyamada, J. J. Org. Chem. 2015, 80, 10431-10436. doi:10.1021/acs.joc.5b01929

68. Banik, S. M.; Medley, J. W.; Jacobsen, E. N. Science 2016, 353, 51-54. doi:10.1126/science.aaf8078

69. Liu, L.; Zhang, T.; Yang, Y.-F.; Zhang-Negrerie, D.; Zhang, X.; Du, Y.; Wu, Y.-D.; Zhao, K. J. Org. Chem. 2016, 81, 4058-4065. doi:10.1021/acs.joc.6b00345

70. Shimogaki, M.; Fujita, M.; Sugimura, T. J. Org. Chem. 2017, 82, 11836-11840. doi:10.1021/acs.joc.7b01141

71. Ngatimin, M.; Frey, R.; Levens, A.; Nakano, Y.; Kowalczyk, M.; Konstas, K.; Hutt, O. E.; Lupton, D. W. Org. Lett. 2013, 15, 5858-5861. doi:10.1021/ol4029308

72. Qurban, J.; Elsherbini, M.; Wirth, T. J. Org. Chem. 2017, 82, 11872-11876. doi:10.1021/acs.joc.7b01571

73. Jobin-Des Lauriers, A.; Legault, C. Y. Org. Lett. 2016, 18, 108-111. doi:10.1021/acs.orglett.5b03345

74. Braddock, D. C.; Cansell, G.; Hermitage, S. A.; White, A. J. P. Chem. Commun. 2006, 1442-1444. doi:10.1039/b600455e

75. Braddock, D. C.; Cansell, G.; Hermitage, S. A. Chem. Commun. 2006, 2483-2485. doi:10.1039/b604130b

76. Ulmer, A.; Stodulski, M.; Kohlhepp, S. V.; Patzelt, P.; Pöthig, A.; Bettray, W.; Gulder, T. Chem. - Eur. J. 2015, 21, 1444-1448. doi:10.1002/chem.201405888

77. Fabry, D. C.; Stodulski, M.; Hoerner, S.; Gulder, T. Chem. - Eur. J. 2012, 18, 10834-10838. doi:10.1002/chem.201201232

78. Stodulski, M.; Goetzinger, A.; Kohlhepp, S. V.; Gulder, T. Chem. Commun. 2014, 50, 3435-3438. doi:10.1039/C3CC49850F

79. Li, M.; Yu, F.; Qi, X.; Chen, P.; Liu, G. Angew. Chem., Int. Ed. 2016, 55, 13843-13848. doi:10.1002/anie.201607248

80. Li, M.; Yu, F.; Chen, P.; Liu, G. J. Org. Chem. 2017, 82, 11682-11690. doi:10.1021/acs.joc.7b01812

81. Qi, X.; Yu, F.; Chen, P.; Liu, G. Angew. Chem., Int. Ed. 2017, 56, 12692-12696. doi:10.1002/anie.201706401

\section{License and Terms}

This is an Open Access article under the terms of the Creative Commons Attribution License (http://creativecommons.org/licenses/by/4.0). Please note that the reuse, redistribution and reproduction in particular requires that the authors and source are credited.

The license is subject to the Beilstein Journal of Organic Chemistry terms and conditions:

(https://www.beilstein-journals.org/bjoc)

The definitive version of this article is the electronic one which can be found at:

doi:10.3762/bjoc. 14.154 